\title{
WHERE HAVE THEY GONE? CHANGES IN OCCUPATIONS USING 1991-2013 NEW ZEALAND CENSUS DATA
}

\author{
Andrew Hancock
}

Statistics New Zealand

\begin{abstract}
Over the period 1991 to 2013 they way in which occupations have been reported and classified in the New Zealand Census of Population and Dwellings has changed. To look at the high level trends, an analysis of the top thirty occupations that have the highest counts in census data in that time period based on the New Zealand Standard Classification of Occupations (NZSCO) has been undertaken. The purpose of this analysis is to have a time-series barometer to see whether respondents change the way in which they respond, and to determine if occupation reporting is reflecting changes in the real world of the New Zealand labour market. A comparison is made using the Australian and New Zealand Standard Classification of Occupations (ANZSCO) to identify if classification changes have an impact. Have some of the old occupations really disappeared or are they being reported differently? Has the way the occupations are classified, and the changes in the classifications caused some interesting trends. What impact has been experienced with the introduction of a trans-Tasman classification? Are there new and emerging occupations in this top group and are there any labour market sectors that are not appropriately represented? The paper discusses the role of an occupational classification in relation to the processing of the responses given to the five yearly population census question on occupation, and questions whether the statistical need for processing survey responses has affected the viability of the classification for labour market analysis.
\end{abstract}

\section{Introduction}

It is the proverbial question for labour market analysis that has been asked for decades - where has that occupation gone? With the introduction of the motor vehicle as a replacement for horses, one of the first questions asked in this space was where have all the blacksmiths gone?

As the world changes, with lifestyles different from what they were ten or even twenty years ago, the radical innovations that have come with technological developments and just the skills required to perform occupations having advanced or crept, occupations have changed in many ways. Some have rebranded themselves, some have maintained a core set of tasks but with new skill requirements, others have emerged out of nowhere and still others have just disappeared. Whatever happened to the milk vendors and the paper deliverers, why are there less posties or bank workers, how much has information and communication technology (ICT) changed the way work has done? Have flexible working conditions or remote access abilities changed the nature and scope of work? Has the labour market really changed that much over time or is there an illusion of change. Fundamentally it could be argued that most occupations are still doing the same basic things they always have. Perhaps it is just the way they are done that has changed. The use of apps on a smartphone or tablet compared to the use of pen and paper, monitoring a production process by watching a computer screen as opposed to loading inputs to and pressing buttons on a machine in a factory all highlight the changing nature of work. 


\section{Purpose}

The purpose of this paper is to analyse the occupation data collected in the Census of Population and Dwellings in the period 1991-2013, and to review the effectiveness of the occupation classifications that are used to collate the data. This has been done by taking the top thirty occupations identified in the census outputs and creating a time-series barometer to analyse the New Zealand labour market. In addition, the analysis provides an opportunity to review and compare any change in coverage of occupations caused by using two classification systems in that time period. An outcome of the work is also an evaluation of the time-series mapping that was created between the New Zealand Standard Classification of Occupations (NZSCO) and the more recent Australian and New Zealand Standard Classification of Occupations (ANZSCO). This mapping was done at a theoretical level and the analysis at the high level helps identify potential operational issues.

\section{Process}

For the period 1991-2013, the thirty occupations that have the highest counts (excluding residual occupation categories) as published in the census outputs (for each census year) are analysed to see what they are, compared against the previous and next census data set, and then observations made that can affect the review of the statistical classifications used to produce the data.

Thirty occupations was chosen as the number to analyse as that represented those occupations reporting 10,000 or more persons employed, and generally those thirty occupations have represented fifty percent of the labour force (as reported in the population census).

The initial analysis began after the 1991 Census of Population and Dwellings as a way of reviewing the introduction of the New Zealand Standard Classification of Occupations 1990 (NZSC090) and to assess its performance as a replacement for the previous classification, the New Zealand Standard Classification of Occupations 1968 (NZSC068). The change in classifications also introduced a change in the conceptual base for classifying occupations, moving from a grouping based on similarity of tasks performed, to a grouping based on skill levels and skill specialisations. Whilst this impacted the scope and nature of many occupations, and how they were classified together, the fundamental range, nature and names of occupations didn't change.

To enable a general time-series analysis to be undertaken, the NZSCO was used as a base given it was the primary classification used for the 1991, 1996 and 2001 Census of Population and Dwellings. With the introduction of ANZSCO in 2006, dual-coding was undertaken whereby each occupation response given in the census was coded to both NZSCO and ANZSCO. The main reason for introducing dual-coding in 2006 was to mitigate the significant time-series disruption that was being created, and to enable a smoother transition and mapping of data with the significant changes that were introduced then. Whilst this was originally going to be a one-off scenario it was decided that the 2011 Census (then 2013) would also be dual-coded. This decision has enabled the analysis of the top thirty to continue but also enabled a comparison against the new classification structure to see if any impact has been generated by a classification change. The ability to continue this process going forward is dependent on whether dual coding is used in the 2018 Census of Population and Dwellings. However it is being recommended that the coding process for 2018 only utilise ANZSCO. 
The base year of 1991 provided the original list of thirty occupations of which 21 of the original list remained in the 2013 NZSCO based listing, recognising that some had seen minor title changes. Each census year, the final output table was sorted by total count and then any residual categories such as 'not stated', or 'response unidentifiable' were removed.

\section{Key Questions}

In undertaking the analysis a number of key questions were identified for resolution. These were:

- Have some of the old occupations (under NZSCO) really disappeared or are they being reported differently?

- Has the way occupations are classified, and the changes in the classifications caused some interesting trends?

- What impact has been experienced with the introduction of a trans-tasman classification?

- Are there new and emerging occupations, and are any labour market sectors not appropriately represented?

Whilst occupations moved in and out of the top thirty table in the period 1991-2013, the analysis focussed on the content as at 1991 and then at 2013. There was also an expectation that emerging sectors of the labour market such as information and communication technology (ICT) and/or environmental occupations would be more obvious or apparent in the 2013 table.

Census practices and the way respondents answer the occupation questions may be having an effect in terms of generic responses that do not have enough information to be precisely classified, that is, there is a subconscious attitude to filling in the forms quickly, giving easy answers and often glorifying job titles. In addition another point of interest was whether the coding tools and the methodology used to create the coding indexes was influenced by the census need to get the responses coded quickly and efficiently at the expense of a wider audience need for detail, for example the coding of occupation titles without referring to the tasks and duties is an efficient process but places significant pressure on getting the job titles into the right categories when the title is vague. The generic responses may artificially inflate many of the top thirty categories as may the coding process focussing on title.

Use of tasks and duties information assists manual coding operators in many instances when trying to code those vague responses but often there is a vagueness applied by the respondent in answering this question as well. Examples would be supervisor (title), supervising (task), teacher (title) teaching (task). In both instances there is insufficient information to make an informed coding decision. However it is recognised that the cost of developing a coding methodology that can fully utilise task and duties information is not a realistic option given the limited amount of text provided by respondents along with much of the task information not being mutually exclusive to one occupation category.

The proliferation of vague occupation titles along with the introduction of extremely role specific titles by human resource departments has not help occupational analysis. The top thirty occupations tend to increase in population as the result of manual coding decisions rather than the ability to easily distinguish them in the classification structure based on tasks and skills. Titles such as team leader, team member, problem manager, project manager, director of first impressions or mobile defoliation detection operator are examples of the problems faced by classification developers particularly when supporting tasks and duties information given in 
statistical surveys does not enable an easy recognition of precise classification categories. This is accompanied by the change in traditional occupation titles being used in a new context, for example the term 'architect' no longer is exclusive to building design but more likely to represent an ICT occupation. However the need to delve into the impacts of these trends is a separate exercise that can be undertaken as part of the future work around the top thirty occupation list.

\section{New Zealand Standard Classification of Occupations (NZSCO)}

NZSCO is a five level hierarchical classification with nine broad major groups and was used as the primary classification for coding census data from 1991 to 2006. The major groups (one digit level) of NZSCO are listed in the following table.

Table 1: NZSCO Major Groups

\begin{tabular}{|l|l|}
\hline 1 & Managers \\
\hline 2 & Professionals \\
\hline 3 & Technicians and Associate Professionals \\
\hline 4 & Clerks \\
\hline 5 & Service and Sales Workers \\
\hline 6 & Agriculture and Fishery Workers \\
\hline 7 & Trades Workers \\
\hline 8 & Plant and Machine Operators and Assemblers \\
\hline 9 & Elementary Occupations \\
\hline
\end{tabular}

The 1991 Census showed that the top thirty categories covered all NZSCO major groups with no real dominance from any one group showing. The occupation with the highest count was Sales Assistant followed by General Clerk with the bottom two occupations in the list being University and Higher Education Lecturer and/or Tutor, and Mixed Livestock Farmer, Mixed Livestock Farm Worker.

Table 2: 1991 Census Top Thirty (NZSCO)

\begin{tabular}{|l|l|}
\hline Sales Assistant & Secondary School Teacher \\
\hline General Clerk & Office Manager \\
\hline Corporate Manager or Managing Director & Information Clerk and Other Receptionist \\
\hline General Labourer & Accountant \\
\hline Retail Manager & Sheep Farmer, Sheep Farm Worker \\
\hline $\begin{array}{l}\text { Secretary (Personal Assistant, Private } \\
\text { Secretary) }\end{array}$ & Slaughterer \\
\hline Dairy Farmer, Dairy Farm Worker & Loader and/or Checker \\
\hline Accounts Clerk & $\begin{array}{l}\text { Commercial Traveller and/or Sales } \\
\text { Representative }\end{array}$ \\
\hline Cleaner & Sales and/or Marketing Manager \\
\hline Primary School Teacher & Carpenter and/or Joiner \\
\hline Registered Nurse & Motor Mechanic \\
\hline Bank Officer & Fruit Grower, Worker \\
\hline Heavy Truck or Tanker Driver & Sewing Machinist \\
\hline Administration and/or Accounting Manager & $\begin{array}{l}\text { University and Higher Education Lecturer } \\
\text { and/or Tutor }\end{array}$ \\
\hline Builder (including Contractor) & $\begin{array}{l}\text { Mixed Livestock Farmer, Mixed Livestock } \\
\text { Farm Worker }\end{array}$ \\
\hline
\end{tabular}


There are some interesting and perhaps not so interesting results from the analysis. Using the NZSCO basis, there was an approximate increase of just over 200,000 persons classified to the top thirty occupations in the period 1991-2013. The critical factor in this though was the significant jump in total population classified in 2006 of approximately 130,000, possibly reflecting an issue with the dual-coding of responses with the introduction of ANZSCO, rather than a natural increase in the labour market. The increase from 2006 to 2013 was similar in nature to those increases that occurred between 1991 and 2001.

The top thirty occupation data shows a reasonable distribution across the NZSCO Major Groups, however it does fail to show any real emergence of Information and Communication Technology (ICT) as a significant phenomenon within the New Zealand labour market. Perhaps this is more due to the nature of the classification structure ie not appropriately addressing ICT jobs as opposed to actual significant growth in numbers reporting.

The biggest loser, so to speak, in the top thirty over the period 1991-2013 period is the occupation of Bank Officer. It should be noted that the decrease recorded for Bank Officer is not the biggest decrease on occupation counts across the time period for Census outputs, it is the biggest decrease of a top thirty occupation (using 1991 as a base). This decrease is probably not unexpected given the increase in Automated Teller Machines (ATMS), internet banking and the reduction in bank branches or outlets. Of interest and requiring further analysis is the occupation of Loader and/or Checker being in the top thirty in 1991 - there is no obvious reason for this. It is also of interest that the occupation of Mixed Livestock Farmer, Mixed Livestock Farm Worker had a significant decline in numbers from 1991 to 1996 which may have been due to a move in the agricultural sector to diversify to crop and livestock production.

Consistently the occupation of Sales Assistant has been the occupation with the highest count in each census, with General Clerk second for all but one and General Manager in third for all but one. An interesting aspect has been the occupation General Labourer being in the top ten of the group for four of the five census periods. This may be a reflection of the nature of responses given to the survey in terms of labourer, factory worker and factory hand with no supporting tasks information to classify them elsewhere.

The occupation of Sales Assistant tends to be a catch-all for all responses relating to retail or sales, and where there is limited detail provided by respondents to classify elsewhere. The same applies to General Clerk and this is perhaps exasperated by responses like office worker, clerical or clerk with no supporting information.

What is generally noticeable in the data is that over time, major group six, seven and nine decreased in terms of representation in the top thirty, whilst Professionals and Managers increased. This tends to be a reasonable reflection of real world change in that manufacturing, production and elementary occupations were in decline, whilst professional occupations increased particularly as skill requirements changed. Whilst correspondingly there was an increase in the total population for major group 5 for service and sales occupations, the number of occupations in this area contributing to the top thirty only went from one to three.

A potential concern with the growth in professionals is skills creep and the proliferation of competing education providers elevating occupational qualification requirements to increase their market share and funding. This is alongside the traditional issue with survey responses that respondents 'glorify' their titles combined with job marketers making titles more grandiose than what is required. For example, sales representatives become sales managers, team leaders 
become project managers, and on it goes. The challenge then becomes ensuring suitable criteria and detail are in place to accurately describe and then classify the occupations concerned.

By the end of the 1991-2013 period, nine occupations had changed in (or dropped out of) the top thirty list, and were replaced by new occupation categories. The overall composition of the list at each point in time, at first glance, seems very similar. The occupational changes were:

Table 2: NZSCO Changes

\begin{tabular}{|l|l|}
\hline \multicolumn{1}{|c|}{1991 (Out) } & \multicolumn{1}{c|}{$\mathbf{2 0 1 3}$ (In) } \\
\hline Bank Officer & Technical Representative \\
\hline Sheep Farmer, Sheep Farm Worker & Caregiver \\
\hline Slaughterer & Crop and Livestock Farmer, Worker \\
\hline Loader and/or Checker & Early Childhood Teacher \\
\hline Carpenter and/or Joiner & Computer Applications Engineer \\
\hline Motor Mechanic & Social Worker \\
\hline Fruit Grower, Worker & Catering Counter Assistant \\
\hline Sewing Machinist & Finance Manager \\
\hline $\begin{array}{l}\text { Mixed Livestock Farmer, Mixed Livestock } \\
\text { Farm Worker }\end{array}$ & Chef \\
\hline
\end{tabular}

An interesting issue is, or course, the rise of Technical Representative and it appears that this is due to the arrival of the occupation title 'Customer Service Representative' and its variations. As the title covers a large number of occupations a decision was made to code to Technical Representative in the NZSCO structure. Computer Applications Engineer has joined the list as many of the ICT occupations that were introduced in ANZSCO only map back to this one NZSCO category. The inclusion of Crop and Livestock Farmer, Worker in the 2013 table is a reflection, as stated above, of the drop in the Mixed Livestock Farmer, Mixed Livestock Farm Worker.

\section{Australian and New Zealand Standard Classification of Occupations (ANZSCO)}

ANZSCO is a five level hierarchical classification with eight major groups. It is the current standard classification for collecting and disseminating data about occupations. It is a joint collaboration with the Australian Bureau of Statistics (ABS) and is the first trans-tasman occupation classification, introduced in 2006.

The major groups (one digit level) of ANZSCO are listed in the following table.

Table 3: ANZSCO Major Groups

\begin{tabular}{|l|l|}
\hline 1 & Managers \\
\hline 2 & Professionals \\
\hline 3 & Technicians and Trades Workers \\
\hline 4 & Community and Personal Service Workers \\
\hline 5 & Clerical and Administrative Workers \\
\hline 6 & Sales Workers \\
\hline 7 & Machinery Operators and Drivers \\
\hline 8 & Labourers \\
\hline
\end{tabular}

In terms of differences between 2006 and 2013 using ANZSCO as a basis, there was limited differences identified in the distribution of the top thirty occupations across ANZSCO major groups. As with the NZSCO, the bulk of the occupations were in the higher skilled major groups 
ie Managers (8) or Professionals (5) whilst Clerical and Administrative Workers also had five. It should be noted that the composition of Major Group 1 in ANZSCO includes farmers who were previously classified into the Agriculture major group in NZSCO, of which there is no direct equivalent in the new classification. Farm workers under ANZSCO are separated out from the farmers and farm managers unlike in the NZSCO scenario where they were combined. This may have impacted on the data distribution and therefore any changes associated with farming occupations in the top thirty eg sheep farmers.

As with the NZSCO basis, Sales Assistant and General Clerk were the two highest responding occupations.

The following table shows the 2013 comparison of the top thirty occupations between the two occupation classifications. It should be noted that the table is not a direct one-to-one comparison as each column is sorted by the occupation count from highest to lowest (within the top thirty). It should also be noted that some differences are in the occupation title only, for example the NZSCO category of Builder (including Contractor) equates to the ANZSCO category of Project Builder

Table 4: Top Thirty Comparison between NZSCO and ANZSCO

\begin{tabular}{|l|l|}
\hline 2013 NZSCO Occupation & 2013 ANZSCO Occupation \\
\hline Sales Assistant & \\
\hline General Clerk & Sales Assistant (General) \\
\hline General Manager & Sales Representative nec \\
\hline Administration Manager & General Clerk \\
\hline General Labourer & Chief Executive or Managing Director \\
\hline Cleaner & Corporate General Manager \\
\hline Technical Representative & Office Manager \\
\hline Registered Nurse & Retail Manager (General) \\
\hline Retail Manager & Labourers nec \\
\hline Caregiver & Commercial Cleaner \\
\hline Primary School Teacher & Personal Care Assistant \\
\hline Sales and/or Marketing Manager & Primary School Teacher \\
\hline Crop and Livestock Farmer, Farm Worker & Sales and Marketing Manager \\
\hline Dairy Farmer, Dairy Farm Worker & Policy and Planning Manager \\
\hline Accountant & Registered Nurse (Medical) \\
\hline Builder (including Contractor) & Project Builder \\
\hline Heavy Truck or Tanker Driver & Accountant (General) \\
\hline Early Childhood Teacher & Dairy Cattle Farmer \\
\hline Secondary School Teacher & Early Childhood (Pre-primary) School Teacher \\
\hline Information Clerk and Other Receptionist & Truck Driver (General) \\
\hline Computer Applications Engineer & Secondary School Teacher \\
\hline Office Manager & Receptionist (General) \\
\hline Social Worker & Storeperson \\
\hline Catering Counter Assistant & Accounts Clerk \\
\hline Accounts Clerk & Mixed Crop and Livestock Farm Worker \\
\hline Secretary & Chef \\
\hline Sales Representative & Program or Project Administrator \\
\hline Finance Manager & Electrician (General) \\
\hline Chef & Motor Mechanic (General) \\
\hline University and Higher Education Lecturer \\
and/or Tutor & Waiter \\
\hline & Finance Manager \\
\hline & \\
\hline & \\
\hline
\end{tabular}


Of interest in the comparison is the emergence of some lower skilled occupations into the list under ANZSCO. For example, Storeperson and Waiter were not expected to be high listing occupations and further analysis on the storeperson occupation by looking at coding changes may identify a cause. An increase in Waiter may be reflective of the general increase in service occupations and/or part-time work with the proliferation of cafes and restaurants.

The introduction of the occupation 'Project or Program Administrator' in the 2013 ANZSCO list reflects the emergence of a widely used, generic title, that is not mutually exclusive to any one category within the occupation classification. A large number of persons responding are in the IT sector and these are classified to a specific occupation category for that. But an analysis of the census responses has identified a significant number of persons reporting the title project manager without any supporting task information. Consequently a catch-all occupation category is included in the occupation classification structure. This category will be reviewed (along with the others in the top thirty) to see if more specific occupation categories can be extracted for inclusion in the classification structure.

It is also worth noting that the occupation of Motor Mechanic (General) has re-emerged into the list, which reflects the up and down nature of the numbers responding with the occupation during the 1991-2013 period. Others that appeared in the earlier list such as Carpenter and/or Joiner are still bubbling below the surface of the top thirty and only miss out due to the higher numbers being reported in other occupations. By 2013 the bottom threshold is closer to 15,000 persons reporting the occupation in the census outputs compared to the original threshold of 10,000 persons reporting. This is also a natural reflection of the increase in persons reporting occupations.

\section{So what does it all mean?}

The top thirty occupation listing using the NZSCO basis represents between $45-48 \%$ of the total population for occupations reported over the 1991-2013 period, noting that there are approximately 565 occupations in that classification structure.

The top thirty occupation listing using the ANZSCO basis represents approximately $38 \%$ of the total population for occupations reported over the 1991-2013 period, noting that there are approximately 1,000 occupations in that classification structure.

Effectively the comparison shows that the census data provides a consistent time-series regardless of the classification structure used, and that the introduction of a new classification in 2006 has not made that much difference. However what the comparison has shown is that some of the expectations for the research outcomes have not been fulfilled.

ICT occupations (that is computing and not telecommunications occupations) had limited coverage in the NZSCO classification as the last review of NZSCO was in 1999 - many ICT occupations that now exist had not emerged at that stage. In effect there were five main NZSCO occupation categories of which there was an exponential growth across System Analysts and Computer Applications Engineers and a decline in Computer Programmers and Computer Operators. With the introduction of ANZSCO in 2006, eighteen ICT occupations are in the classification structure and these primarily map back to the two main NZSCO occupations stated before (Systems Analyst and Computer Applications Engineer). Whilst there is a significant increase in the titles and jobs in the sector there has not been an emergence into the top thirty 
listing, although Systems Analyst and Developer Programmer are becoming future contenders for inclusion. A challenge with the sector is that it is the most volatile and dynamic sector of the labour market with job titles rapidly changing, and increasing adoption of traditional non-ICT titles being brought in. Potentially some respondents may be lost in other related categories.

In terms of environmental occupations emerging into the top thirty list, again this is somewhat impacted by the limited coverage within NZSCO as compared to ANZSCO. An issue that also impacts the coverage within the ANZSCO classification is the difficulty in determining the concept of green jobs and whether an outcome on that affects what occupation categories are included in the classification.

The identification of green jobs or occupations is not an easy process. It is not a case of adding the words 'environmental', 'green', 'sustainability' or 'renewable' to existing titles or tasks contained within job descriptions. The issue is much wider than that. For example, has the New Zealand economy been 'greened' to the extent that new industries, qualifications and occupations are coming into existence, or is the 'greening' of the economy and labour market still in its infancy? The 'greening' of the labour market is slowly occurring but not at a noticeable rate at the high levels of analysis this research is undertaking.

\section{Next steps for research}

Whilst the top thirty list has provided some indication of stability across time, there is a need for further analysis of the impact of coding methodology on the data to understand whether decisions made to support automated coding of responses have compromised the intent and content of the classification. In addition, a comparison of manual coding decisions may also highlight why some of the occupations continue to appear in the list.

Going forward there is a need to analyse the raw responses to better understand the nature of the responses being given, in particular is there sufficient information from the titles alone, or is there a need to get better tasks and duties information to assist manual coding decisions. The lack of tasks and duties information and the vagueness of many occupation responses impacts on the decisions made.

Another step to undertake is a review of the next most popular occupations (possibly in the 5,000-10,000 responses) to see if this helps answer key questions. Are there occupational trends appearing at the next level that will emerge in the top thirty if 2018 Census data is analysed? Moving the analysis down the rankings so to speak may provide a different picture or more of the same.

A compounding factor in the classification development for both NZSCO and ANZSCO is that the classification structures attempt to reflect the real world of the labour market. The challenge in this space has been the information supplied by industry in terms of numbers employed in a job or occupation compared to the numbers actually reporting. There is often a discrepancy and this is also a reflection of the reluctance by respondents to report their jobs as per their designation. Alongside this is the skills creep factor introduced by the proliferation of education providers competing with each other to attract students by offering qualifications that are at a level higher than really required for an occupation. For the classification developers this is a significant issue to work through when building the classification structures and coding indexes, and there may be a flow on effect to why some occupations are appearing in the top thirty listing. 
Whether ANZSCO has the right coverage of occupations for the New Zealand labour market needs to be further analysed at the detailed level of the classification. The competing needs of census data, migration data, immigration and skill shortage requirements, and the provision of career development information highlights the need for ongoing time-series analysis. The top thirty list does provide a basic barometer which provides some indication of where issues may lie. A factor that may need further analysis though is the comparison of New Zealand census outputs with Australian to see if the same occupations are occurring using the ANZSCO structure.

\section{Conclusion}

The top thirty occupation list has alluded to a number of ongoing issues that exist in processing responses given to the occupation questions in the Census of Population and Dwellings. The list does provide an interesting analysis of broad areas of the labour market but the analysis clearly shows that the nature of responses combined with the need to efficiently process those responses has influenced the type of information that can be produced for analysing the labour market. Understanding the decline in some occupational categories is often due to understanding real world changes (for example in banking) but other changes are not always obvious.

The introduction of a trans-tasman classification has, at the highest level, not shown any real change in the labour market sectors that are covered by the top thirty list. There is also the implication that the consistency that has been produced over time is an accurate reflection of the mapping between the NZSCO and ANZSCO. However further analysis of census dual-coding may ascertain more issues.

The lack of perceived emerging sectors whilst an interesting outcome of this research may be alleviated by extending the research to include the 2018 census data.

Further work is required to fully answer the key questions posed for this research however the exercise has provided an interesting barometer of the New Zealand labour market based upon census data over the period 1991-2013. 